\title{
A Cyclin D1 (CCND1) Gene Polymorphism Contributes to Susceptibility to Papillary Thyroid Cancer in the Turkish Population
}

\author{
Turkan Aytekin ${ }^{1 *}$,Alper Aytekin ${ }^{2}$, Gokturk Maralcan ${ }^{2}$, M Avni Gokalp ${ }^{2}$, Dogukan \\ Ozen $^{3}$, Ersin Borazan ${ }^{2}$, Latif Yilmaz ${ }^{2}$
}

\begin{abstract}
Cyclin D1 is an important positive regulator of the G1/S phase of the cell cycle. We investigated the association between the CCND1 G870A polymorphism and susceptibility to papillary thyroid cancer in Turkish people. This study covered 102 patients with papillary thyroid cancer and 174 healthy controls. CCND1 genotyping was determined by the PCR-RFLP method. We found that the A allele frequency was higher in the cases than in the controls $(p=0.042)$. On stratification analysis, papillary thyroid cancer risk was significantly elevated in individuals older than 45 years with the $A$ allele $(O R=1.91,95 \% \mathrm{CI}, 1.09-3.35, p=0.024)$ and in females with the A allele $(\mathrm{OR}=1.73,95 \% \mathrm{CI}, 1.06-2.84, \mathrm{p}=\mathbf{0 . 0 2 9})$, compared to the $\mathrm{G}$ allele. According to the subject age, there was an increased papillary thyroid cancer risk for the individuals older than 45 years with the AA genotype $(O R=2.28$, 95\% CI, 1.02-5.13, $\mathrm{p}=\mathbf{0 . 0 4 6}$ ) compared to the AG+GG combined genotypes. In conclusion, it is suggested that the CCND1 G870A polymorphism may contribute to the susceptibility to papillary thyroid cancer, especially in those who were older subjects (45 years old) and female, in the Turkish population.
\end{abstract}

Keywords: Papillary thyroid cancer - cyclin D1 gene - polymorphism - Turkish population

Asian Pac J Cancer Prev, 15 (17), 7181-7185

\section{Introduction}

Thyroid cancer is the most common malignancy of the endocrine system and contributes to more than $50 \%$ of all deaths from endocrine cancers (Du et al., 2013). Among thyroid cancers, papillary thyroid cancer (PTC) is the most, accounting for $80-90 \%$ of all the thyroid malignancies (Ranjbari et al., 2013; Wang et al., 2013). Environmental factors such as radiation exposure, smoking, diet (iodine deficiency), and hormonal factors contribute to PTC development, and genetic factors are also related to the susceptibility of developing PTC (Sturgis and Li, 2009; Du et al., 2013; Ozdemir et al., 2013). Genetic polymorphism existing in the human genome plays an important role in the development of cancers (Wang et al., 2013).

Disturbances in the control of cell cycle play an important role in cancer formation (Sherr, 1996). Cyclin $\mathrm{D} 1$ is a key regulatory protein in the cell cycle, playing a critical role in the transition from $\mathrm{G} 1$ to $\mathrm{S}$ phase of the cell cycle. Cyclin D1 regulates cell cycle progression by activating cyclin dependent kinase 4 (CDK4) and cyclin dependent kinase 6 (CDK6), which in turn phosphorylate the retinoblastoma $(\mathrm{Rb})$ protein. The phosphorylation of $\mathrm{Rb}$ releases the transcriptional factor E2F, which then activates a number of downstream genes necessary for cell cycle progression. This event lead to progression through G1/S transition (Cortessis et al., 2003; Huang et al., 2006a; Knudsen, 2006; Knudsen et al., 2006).

Cyclin D1 is encoded by the CCND1 gene located on chromosome 11q13. Betticher et al. (1995) identified G870A polymorphism in exon 4 of the CCND1 gene. This polymorphism doesn't cause to an amino acid change, but CCND1 mRNA is alternatively spliced to produce two transcripts. The CCND1 G870 allele splices transcript a, whereas the CCND1 870A allele mainly splices transcript $\mathrm{b}$. The protein encoded by transcript $\mathrm{b}$, cyclin D1b, however, lacks the degradation signal encoded by exon 5 and hence may have a longer halflife, resulting in deregulated cell proliferation. Increased expression of cyclin D1 may lead to premature cell passage through $\mathrm{G} 1 / \mathrm{S}$ transition, which result in the propagation of unrepaired DNA damage, accumulation of genetic errors, and a selective growth advantage for the altered cells (Sawa et al., 1998; Zheng et al., 2001; Knudsen et al., 2006; Huang et al., 2006a; Akkız et al., 2010, Zeybek et al., 2013).

A number of studies have suggested that the CCND1 G870A polymorphism is associated with susceptibility to various cancers, including bladder cancer (Wang et al., 2002), breast cancer (Yu et al., 2008), colorectal

${ }^{1}$ Department of Biology, Faculty of Arts and Sciences, ${ }^{2}$ Department of General Surgery, Faculty of Medicine, University of Gaziantep, Gaziantep, ${ }^{3}$ Department of Biostatistics, Faculty of Veterinary Medicine, University of Ankara, Ankara, Turkey * For correspondence: turkanayte@hotmail.com 
cancer (Porter et al., 2002; Hong et al., 2005), esophageal adenocarcinoma (Casson et al., 2005), endometrial cancer (Kang et al., 2005), cervical cancer (Catarino et al., 2005), head and neck cancer (Zheng et al., 2005; Liu et al., 2011), hepatocellular carcinoma (Akk1z et al., 2010), childhood acute lymphoblastic (Hou et al., 2005), lung cancer (Qiuling et al., 2003; Li et al., 2012), prostate cancer (Wang et al., 2003) and glioblastoma multiforma (Zeybek et al., 2013).

There have been no reports about the association of the CCND1 G870A polymorphism with PTC in literature. In this study, we investigated the CCND1 G870A allele and genotype frequencies in patients with PTC and healthy controls, and demonstrated the association between the CCND1 G870A polymorphism and risk of developing PTCs in Turkish population.

\section{Materials and Methods}

\section{Subjects}

A total of 102 patients with PTC and 174 healthy controls were qualified for this study. We performed a hospital-based case-control study. All samples were taken at the Department of General Surgery, Gaziantep University, between July 2012 and September 2014. The healthy, unrelated and cancer-free subjects, who visited hospital for a routine health checkup, were recruited for the study as controls. The samples were collected from PTC patients before any chemotherapeutic or radiation therapy treatment had been started. All the PTC patients and controls were citizens of the Turkish Republic. All samples were taken after informed consent, according to the declaration of Helsinki. Ethics committee approval required for the study was obtained from the Gaziantep University Medical Faculty Local Ethics Committee.

\section{DNA extraction}

Blood samples obtained from the PTC patients and controls were collected into tubes containing EDTA. Genomic DNA was isolated from $10 \mathrm{ml}$ blood samples in tubes with EDTA by the method of Miller et al. based on sodium dodecyl sulphate lysis, ammonium acetate extraction, and ethanol precipitation (Miller et al., 1988).

\section{Genotyping of CCND1 G870A polymorphism}

Polymerase chain reaction-restriction fragment length polymorphism (PCR-RFLP) analysis was performed to determine the CCND1 G870A polymorphism. The 212 bp DNA fragment containing the $G$ to A polymorphic site in the CCND1 was amplified using specific primers (Ella Biotech $\mathrm{GmbH}$, Deutschland) as follows: 5'- AGTTCATTTCCAATCCGCCC -3' and 5'-TTTCCGTGGCACTAGGTGTC -3'. The reaction mixture consisted of $0.2 \mu \mathrm{g}$ of genomic DNA, $0.6 \mathrm{mmol} / \mathrm{L}$ of each primer, $0.2 \mu \mathrm{mol} / \mathrm{L}$ of each $\mathrm{dNTP}, 0.25 \mathrm{mmol} / \mathrm{L}$ $\mathrm{MgCl}_{2}, 1 \mathrm{X}$ Taq buffer and $2.5 \mathrm{U}$ of Taq DNA polymerase (MBI Fermentas, Lithuania) to a final volume of $50 \mu \mathrm{L}$. The reaction mixture was initially denatured at $94^{\circ} \mathrm{C}$ for 5 minutes, followed by 35 cycles of a denaturation step at $94^{\circ} \mathrm{C}$ for 1 minute, an annealing step at $60^{\circ} \mathrm{C}$ for 1 minute, and an extension step at $72^{\circ} \mathrm{C}$ for 1 minute. The PCR programme was completed by a final extension step at $72^{\circ} \mathrm{C}$ for 7 minutes. The PCR products were digested with $5 \mathrm{U}$ MspI enzyme (MBI Fermentas, Lithuania) at $37^{\circ} \mathrm{C}$ for overnight and electrophoresed on $4 \%$ agarose gel. The allele types were determined as follows: two fragments of 175 and $37 \mathrm{bp}$ for AA genotype, three fragments of 141,37 and $34 \mathrm{bp}$ for GG genotype, and four fragments of 175, 141, 37 and 34 bp for AG genotype (Sobti et al., 2006) (Figure 1).

\section{Statistical analyses}

All statistical analyses were carried out using SPSS version 14.01 for Windows (SPSS Inc., Chicago, IL). Hardy-Weinberg equilibrium analyses were performed to compare observed and expected genotype frequencies using a $\chi^{2}$ test $(\mathrm{df}=1)$. Pearson's $\chi^{2}$ test was used to determine whether there was any significant difference in allele and genotype frequencies between patients and controls. Differences in the distributions of demographic characteristics between the cases and controls were evaluated using the Student's t-test (for continuous variables) and $\chi^{2}$ test (for categorical variables). The associations between the CCND1 G870A genotypes and the risk of PTC were estimated by computing the ORs and their 95\%CIs from logistic regression analyses with adjustment for age, sex, smoking status and alcohol use. Statistical modeling was performed on the relative risk of the AA genotype or the GA genotype against the GG genotype independently. Additionally, the relative risk of the AA genotype against the GA + GG genotype or the AA + GA genotype against the GG genotype were calculated using logistic regression model. Probability levels less than 0.05 were used as a criterion of significance.

\section{Results}

There were 102 PTC cases and 174 healthy controls included in this study. The cases and controls were adequately matched by sex, age groups $(\leq 45$ years old and $>45$ years old), smoking status and alcohol use. The mean ages of case and control groups were 46.18 \pm 12.80 $($ mean \pm SD) and $41.92 \pm 17.83$, respectively.

The distributions of the CCND1 genotypes were in Hardy-Weinberg equilibrium in the PTC patients $\left(\mathrm{n}=102, \chi^{2}(1)=2.146, \mathrm{p}=0.143\right)$ and the controls $(\mathrm{n}=174$, $\left.\chi^{2}(1)=0.547, \mathrm{p}=0.459\right)$. Distributions of the CCND1 genotype and allele frequency between cases and controls were analyzed using Pearson's $\chi^{2}$ test and shown in Table 1. The A allele frequency was higher in cases (0.637) than that in controls (0.549), and this difference was statistically significant $(\mathrm{p}=0.042)$. The frequencies of the

Table 1. Distributions of the CCND1 Genotype and Allele Frequency Between Cases and Controls

\begin{tabular}{llcrc}
\hline & & Controls n $(\%)$ & Cases n (\%) & p-value \\
\hline Genotypes & AA & $50(29)$ & $38(37)$ & 0.085 \\
& AG & $91(52)$ & $54(53)$ & \\
Alleles & GG & $33(19)$ & $10(10)$ & \\
& A & $191(55)$ & $130(64)$ & 0.042 \\
& G & $157(45)$ & $74(36)$ & \\
\hline
\end{tabular}


Table 2. Stratification Analysis of CCND1 Allele and Genotype Frequency in PTC

\begin{tabular}{|c|c|c|c|c|c|}
\hline & & $\begin{array}{l}\text { Controls } \\
\text { No. }(\%)\end{array}$ & \begin{tabular}{c}
\multicolumn{2}{c}{ Cases } \\
No. $(\%)$
\end{tabular} & OR $(95 \% \mathrm{CI})$ & p-value \\
\hline \multicolumn{6}{|l|}{$\mathrm{Sex}^{\mathrm{a}}$} \\
\hline \multirow[t]{4}{*}{ Female } & $\mathrm{A}$ & $95(59)$ & $100(69)$ & $1.73(1.06-2.84)$ & 0.029 \\
\hline & $\mathrm{G}$ & $65(41)$ & $44(31)$ & 1 (Reference) & \\
\hline & AA & $28(35)$ & $30(42)$ & $1.63(0.78-3.41)$ & 0.194 \\
\hline & $\mathrm{GG}+\mathrm{AG}$ & $52(65)$ & $42(58)$ & 1 (Reference) & \\
\hline \multirow[t]{4}{*}{ Male } & A & $96(51)$ & $30(50)$ & $0.96(0.53-1.72)$ & 0.879 \\
\hline & $\mathrm{G}$ & $92(49)$ & $30(50)$ & 1 (Reference) & \\
\hline & AA & $22(23)$ & $8(27)$ & $1.14(0.43-3.00)$ & 0.789 \\
\hline & $\mathrm{GG}+\mathrm{AG}$ & $72(77)$ & $22(73)$ & 1 (Reference) & \\
\hline \multicolumn{6}{|c|}{$\mathrm{Age}^{\mathrm{b}}$ (years) } \\
\hline \multirow[t]{4}{*}{$\leq 45$} & A & $114(56)$ & $62(60)$ & $1.05(0.63-1.75)$ & 0.844 \\
\hline & G & $90(44)$ & $42(40)$ & 1 (Reference) & \\
\hline & AA & $32(31)$ & $16(31)$ & $0.80(0.35-1.84)$ & 0.598 \\
\hline & $\mathrm{GG}+\mathrm{AG}$ & $70(69)$ & $36(69)$ & 1 (Reference) & \\
\hline \multirow[t]{4}{*}{$>45$} & A & $77(53)$ & $68(68)$ & $1.91(1.09-3.35)$ & 0.024 \\
\hline & $\mathrm{G}$ & $67(47)$ & $32(32)$ & 1 (Reference) & \\
\hline & AA & $18(25)$ & $22(44)$ & $2.28(1.02-5.13)$ & 0.046 \\
\hline & $\mathrm{GG}+\mathrm{AG}$ & $54(75)$ & $28(56)$ & 1 (Reference) & \\
\hline \multicolumn{6}{|c|}{ Alcohol use $\mathrm{c}^{\mathrm{c}}$} \\
\hline \multirow[t]{4}{*}{ Never } & A & $159(54)$ & $122(64)$ & $1.33(0.90-1.96)$ & 0.160 \\
\hline & G & $137(46)$ & $70(36)$ & 1 (Reference) & \\
\hline & AA & $38(26)$ & $36(38)$ & $1.51(0.83-2.75)$ & 0.181 \\
\hline & $\mathrm{GG}+\mathrm{AG}$ & $110(74)$ & $60(63)$ & 1 (Reference) & \\
\hline \multirow[t]{4}{*}{ Ever } & A & $32(62)$ & $8(67)$ & $1.32(0.35-5.04)$ & 0.690 \\
\hline & $\mathrm{G}$ & $20(38)$ & $4(33)$ & 1 (Reference) & \\
\hline & AA & $12(46)$ & $2(33)$ & $0.57(0.09-3.77)$ & 0.555 \\
\hline & $\mathrm{GG}+\mathrm{AG}$ & $14(54)$ & $4(67)$ & 1 (Reference) & \\
\hline \multicolumn{6}{|c|}{ Smoking status ${ }^{\mathrm{d}}$} \\
\hline \multirow[t]{2}{*}{ Never } & A & $91(49)$ & $86(65)$ & $1.89(1.17-3.04)$ & 0.010 \\
\hline & $\mathrm{G}$ & $95(51)$ & $46(35)$ & 1 (Reference) & \\
\hline \multirow[t]{2}{*}{ Ever } & A & $100(62)$ & $44(61)$ & $0.75(0.40-1.41)$ & 0.380 \\
\hline & G & $62(38)$ & $28(39)$ & 1 (Reference) & \\
\hline
\end{tabular}

*Abbreviations: $\mathrm{CI}$, confidence interval; OR, odds ratio; ${ }^{\text {a Adjusted for age and smoking status; }}$ ${ }^{\mathrm{b}}$ Adjusted for sex and smoking status; 'Adjusted for age; ${ }^{\mathrm{A} A d j u s t e d ~ f o r ~ a g e ~ a n d ~ s e x ~}$

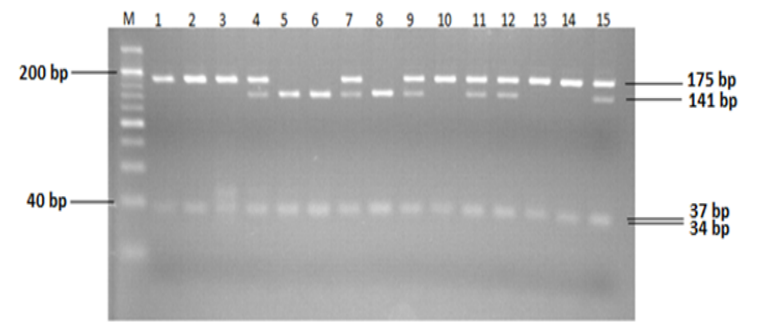

Figure 1. RFLP Analysis of the CCND1 Genotypes. M:20-bp DNA marker. Cases 1,2,3,10,13,14: AA genotype; cases 4,7,9,11,12,15: AG genotype; cases 5,6,8: GG genotype

AA, AG, and GG genotypes were 37,53 , and $10 \%$ in the cases, respectively, and 29,52, and $19 \%$ in the controls respectively, but the difference was not statistically significant $(\mathrm{p}=0.085)$.

To evaluate the risk of PTC according to the CCND1 G870A allele and genotype, logistic regression analysis was conducted with adjustment for age, sex, smoking status and alcohol use. Using the G allele as the reference allele, the subjects carrying the A allele had 2.36-fold increase in the risk of PTC $(95 \% \mathrm{CI}, 1.54-3.61)$, but $\mathrm{p}$-value was not significant $(\mathrm{p}=0.151)$. Compared to individuals with the GG genotype, individuals with the AA and AG genotype exhibited increased PTC risk with adjusted ORs of 2.04 (95\%CI, 0.85-4.85) and 1.66 (95\% CI, 0.74-3.75), respectively but this was statistically insignificant ( $\mathrm{p}=0.109$ and 0.220 , respectively).
Table 2 shows the CCND1 allele frequencies in PTC cases and controls stratified by sex, age ( $\leq 45$ years old and $>45$ years old), smoking status and alcohol use. When we used the $G$ allele as a reference allele, we found that the PTC risk was statistically significant in older than 45 years individuals with the A allele $(\mathrm{OR}=1.91,95 \% \mathrm{CI}, 1.09$ $3.35, \mathrm{p}=0.024)$. Additionally, females with the A allele had approximately 2 -fold increased risk for development of PTC (95\%CI, 1.06-2.84, p=0 .029) compared to the $\mathrm{G}$ allele. According to distribution of alleles, there was not association between smoking and alcohol use and PTC risk $(\mathrm{p}>0.05)$.

The stratification of the analysis according to the subjects' age ( $\leq 45$ years old and $>45$ years old) lead to the observation that there was a statistically significant 2.28-fold increase of PTC risk for the older than 45 years carrying the AA genotype (95\%CI, 1.02-5.13, p=0.046) compared with the AG+GG combined genotypes (Table 2).

\section{Discussion}

The loss of regulatory control of cell cycle, leading to uncontrolled cell proliferation, is a hallmark of cancer. Cyclins, the regulatory subunits of cyclin dependent kinases (CDKs), control the passage of proliferating cells through key checkpoints in the cell cycle (Sherr and Roberts, 1995; Hall and Peters, 1996). Cyclin D1 is one of the proteins that play an important role in the transition from the $\mathrm{G} 1$ phase to the $\mathrm{S}$ phase of the cell cycle. Cyclin D1 overexpression has been described in many human cancers (Knudsen et al., 2006). In the first study that implicated cyclin D1 in human tumors, CCND1 was linked in parathyroid adenomas to the parathyroid hormone gene (Motokura et al., 1991). Cyclin D1 expression has been reported to occur in some papillary thyroid carcinoma (Temmim et al., 2006). The CCND1 gene has a single base polymorphism (G870A) in exon 4 splice site. The G870A polymorphism at the exon 4 splice site has been shown to increase the frequency of alternative splicing. The protein encoded by alternate transcript lacks the carboxy-terminal region encoded by exon 5 . As a result, the carboxy-terminal end of the alternate transcript lacks sequences important for protein turnover and thus may have a longer half-life (Betticher et al., 1995).

In this study was investigated association between the CCND1 G870A polymorphism and PTC risk in Turkish population. Using the $\mathrm{G}$ allele as the reference allele, individuals carrying the A allele had a 2.36-fold increase in the risk for PTC. In addition to this, compared with the GG genotype, AA and AG genotypes increased risk but not significantly associated with the risk of PTC. Several previous studies have reported no associations between the CCND1 G870A polymorphism and risk for various human solid tumors, including bladder (Cortessis et al., 2003), breast and colorectal cancers (Grieu et al., 2003), esophageal adenocarcinoma (Liu et al., 2010) and oral squamous cell carcinoma (Gomes et al., 2008). In contrast with these studies, some authors observed that AA genotype was a risk factor for urinary bladder (Wang et al., 2002), colorectal (Jiang et al., 2006), endometrial (Kang 


\section{Turkan Aytekin et al}

et al., 2005), prostate (Wang et al., 2003), hepatocellular (Akkız et al., 2010), esophageal (Casson et al., 2005), and head-neck (Zheng et al., 2001) cancers in different ethnic origins. These controversial results suggest that the effect of genotype on tumor behavior may exhibit some degree of tissue specity (Mattihas et al., 1998). It is possible that these conflicting results in part reflect the many different mechanisms through which deregulated expression of CCND1 can occur in cancer (Catarino et al., 2005). Several factor, such as cancer type, geographic or ethnic differences, environmental and other factors, may play a significant role in different results.

Various studies showed that the CCND1 G870A polymorphism effect on cancer changed according to sex. Shi et al. (2003) indicated that the CCND1 AA genotype was associated with a significantly increased risk for lung cancer and the effects were more evident in males. Huang et al. (2006b) reported that the increased risk for colorectal cancer was found in males with the AA or AG genotype in Taiwan population. Additionally, in Non-Hispanic White population, high risk for squamous cell carcinoma of the head and neck was detected in female carrying the AA genotype (Zheng et al., 2001). In stratified analysis, we observed that the increased risk was in female with the A allele. Thyroid cancers are 2-3 fold more common in females than males (Brown et al., 2011). In our study, female ratio was $71 \%$ among patients with PTC. It seems that the CCND1 G870A polymorphism may not be a susceptibility marker for PTC of men in Turkish population, but a larger population studies are needed to confirm this finding.

PTC is more common in older age (Schlumberger, 1998; Pacini et al., 2006). In addition to this, the prognosis of PTC is better for younger patients than for patients who are older than 45 years (Zhang et al., 2013). In the present study, PTC risk was found to be significantly higher in individuals over the age of 45 carrying the AA genotype. Contrary to our results, previous studies reported that the increased risk was in younger subjects who carrying the AA or the AA+AG genotypes for different cancer types, including oral premalignant lesion (Huang et al., 2006a), lung cancer (Qiuling et al., 2003) and squamous cell carcinoma of the head and neck (Zheng et al., 2001).

In conclusion, this is the first study to demonstrate the association between the CCND1 G870A polymorphism and risk of papillary thyroid cancer. Our results suggest that the CCND1 G870A polymorphism may contribute to the susceptibility to papillary thyroid cancer, especially in those who were older subjects ( $>45$ years old) and female, in Turkish population. This study has some limitations. First, it was a hospital-based case-control study, and subjects were selected at a single institution (Gaziantep University, Research Hospital) and thus may have been unrepresentative of papillary thyroid cancer patients in the general population. Second, the statistical power of our study was limited because of the relatively small number of cases enrolled. Third, we also limited our study to Turkish population. Therefore, larger prospective studies are needed to elucidate the precise role of the CCND1 G870A polymorphism in papillary thyroid cancer.

\section{Acknowledgements}

The authors thank all the individuals who participated in this study and Gaziantep University, Scientific Research Projects Governing Unit for financial support.

\section{References}

Akkız H, Bayram S, Bekar A, Akgollu E, Ozdil B (2010). Cyclin D1 G870A polymorphism is associated with an increased risk of hepatocellular carcinoma in the Turkish population: Case-control study. Cancer Epidemiol, 34, 298-302.

Betticher DC, Thatcher N, Altermatt HJ, et al (1995). Alternate splicing produces a novel cyclin D1 transcript. Oncogene, 11, 1005-11.

Brown RL, de Souza JA, Cohen EEW (2011). Thyroid Cancer: burden of illness and management of disease. J Cancer, 2 , 193-9.

Casson AG, Zheng Z, Evans SC, et al (2005). Cyclin D1 polymorphism (G870A) and risk for esophageal adenocarcinoma. Cancer, 104, 730-9.

Catarino R, Matos A, Pinto D, et al (2005). Increased risk of cervical cancer associated with cyclin D1 gene A870G polymorphism. Cancer Genet Cytogen, 160, 49-54.

Cortessis VK, Siegmund K, Xue S, Ross RK, Yu MC (2003). A case-control study of cyclin D1 CCND1 870A $\rightarrow$ G polymorphism and bladder cancer. Carcinogenesis, $\mathbf{2 4 ,}$ 1645-50.

Du Y, Han LY, Li DD, et al (2013). Associations between XRCC1 Arg399Gln, Arg 194Trp, and Arg280His polymorphism and risk of differentiated thyroid carcinoma: a meta-analysis. Asian Pac J Cancer Prev, 14, 5483-7.

Gomes CC, Drummond SN, Guimaraes ALS, et al (2008). P21/WAF1 and cyclin D1 variants and oral squamous cell carcinoma. J Oral Pathol Med, 37, 151-6.

Grieu F, Malaney S, Ward R, Joseph D, Iacopetta B (2003). Lack of association between CCND1 G870A polymorphism and the risk of breast and colorectal cancers. Anticancer Res, 23, 4257-9.

Hall M, Peters G (1996). Genetic alterations of cyclins, cyclindependent kinases, and cdk inhibitors in human cancer. $A d v$ Cancer Res, 68, 67-108.

Hong Y, Eu KW, Seow-Choen F, Fook-Chong S, Cheah PY (2005). GG genotype of cyclin D1 G870A polymorphism is associated with increased risk and advanced colorectal cancer in patients in Singapore. Eur J Cancer, 41, 1037-44.

Hou X, Wang S, Zhou Y, et al (2005). Cyclin D1 gene polymorphism and susceptibility to childhood acute lymphoblastic leukemia in a Chinese population. Int $J$ Hematol, 82, 206-9.

Huang M, Spitz MR, Gu J, et al (2006a). Cyclin D1 gene polymorphism as a risk factor for oral premalignant lesions. Carcinogenesis, 27, 2034-7.

Huang WS, Tang R, Lin PY, et al (2006b). Impact of the cyclin D1 A870G polymorphism on susceptibility to sporadic colorectal cancer in Taiwan. Dis Colon Rectum, 49, 602-8.

Jiang J, Wang J, Suzuki S, et al (2006). Elevated risk of colorectal cancer associated with the AA genotype of the cyclin D1 A870G polymorphism in an Indian population. J Cancer Res Clin Oncol, 132, 193-9.

Kang S, Kim JW, Park NH, et al (2005). Cyclin D1 polymorphism and the risk of endometrial cancer. Gynecol Oncol, 97, 431-5.

Knudsen KE (2006). The cyclin D1b splice variant: an old oncogene learns new tricks. Cell Division, 15, 1-12.

Knudsen KE, Diehl JA, Haiman CA, Knudsen ES (2006). Cyclin D1: polymorphism, aberrant splicing and cancer risk. 
Oncogene, 25, 1620-8.

Li Y, Zhang S, Geng JX, Yu Y (2012). Effects of the cyclin D1 polymorphism on lung cancer risk - a meta-analysis. Asian Pac J Cancer Prev, 13, 2325-8.

Liu G, Cescon DW, Zhai R, et al (2010). p53 Arg72Pro, MDM2 T309G and CCND1 G870A polymorphisms are not associated with susceptibility to esophageal adenocarcinoma. Dis Esophagus, 23, 36-9.

Liu W, Zhu E, Wang R, et al (2011). Cyclin D1 gene polymorphism A870G, is associated with an increased risk of salivary gland tumors in the Chinese population. Cancer Epidemiol, 35, 12-7.

Matthias C, Branigan K, Jahnke V, et al (1998). Polymorphism within the cyclin D1 gene is associated with prognosis in patients with squamous cell carcinoma of the head and neck. Clin Cancer Res, 4, 2411-8.

Miller SA, Dykes DD and Polesky HS (1998). Simples salting out procedure for extracting DNA from human nucleated cells. Nucleic Acid Res, 16, 1215-9.

Motokura T, Bloom T, Kim HG, et al (1991). A novel cyclin encoded by a bcl1-linked candidate oncogene. Nature, 350, $512-5$.

Ozdemir S, Uludag A, Silan F, et al (2013). Possible roles of the xenobiotic transporter p-glycoproteins encoded by the MDR1 $3435 \mathrm{C}>\mathrm{T}$ gene polymorphism in differentiated thyroid cancers. Asian Pac J Cancer Prev, 14, 3213-7.

Pacini F, DeGroot LJ (2006). Thyroid Neoplasia, Eds DeGroot LJ, Jameson JL. Endocrinologyn (5th ed). Philadelphia, Elsevier Saunders, pp 2147-80.

Porter TR, Richards FM, Houlston RS, et al (2002). Contribution of cyclin d 1 (CCND1) and E-cadherin (CDH1) polymorphisms to familial and sporadic colorectal cancer. Oncogene, 21, 1928-33.

Qiuling S, Yuxin Z, Suhua Z, et al (2003). Cyclin D1 gene polymorphism and susceptibility to lung cancer in a Chinese population. Carcinogenesis, 24, 1499-503.

Ranjbari N, Almasi S, Mohammadi-asl J, Rahim F (2013). BRAF mutations in Iranian patients with papillary thyroid carcinoma. Asian Pac J Cancer Prev, 14, 2521-3.

Sawa H, Ohshima TA, Ukita H, et al (1998). Alternatively spliced forms of cyclin D1 modulate entry into the cell cycle in an inverse manner. Oncogene, 16, 1701-12.

Schlumberger MJ (1998). Papillary and follicular thyroid carcinoma. N Eng J Med, 338, 297-306.

Sherr CJ, Roberts JM (1995). Inhibitors of mammalian G1 cyclin-dependent kinases. Genes Dev, 9, 1149-63.

Sherr CS (1996). Cancer cell cycles. Science, 274, 1672-7.

Sobti RC, Kaur P, Kaur S, et al (2006). Effect of cyclin D1 (CCND1) polymorphism on susceptibility to lung cancer in a North Indian population. Cancer Genet Cytogen, $\mathbf{1 7 0}$, 108-14.

Sturgis EM, Li G (2009). Molecular epidemiology of papillary thyroid cancer: in search of common genetic associations. Thyroid, 19, 1031-4.

Temmim L, Ebraheem K, Baker H, Sinowatz F (2006). Cyclin D1 protein expression in human thyroid gland and thyroid cancer. Anat Histol Embryol, 35, 125-9.

Wang L, Habuchi T, Takahashi T, et al (2002). Cyclin D1 gene polymorphism is associated with an increased risk of urinary bladder cancer. Carcinogenesis, 23, 257-64.

Wang L, Habuchi T, Mitsumori K, et al (2003). Increased risk of prostate cancer associated with AA genotype of cyclin D1 gene A870G polymorphism. Int J Cancer, 103, 116-20.

Wang YX, Li ML, Yu SG, et al (2013). The association between the Survivin A9194G exon polymorphisms and papillary thyroid carcinoma risk in the Han Chinese population. Pathol Res Pract, 209, 151-4.
DOI:http://dx.doi.org/10.7314/APJCP.2014.15.17.7181

Cyclin D1 Polymorphism and Risk of Papillary Thyroid Cancer

Yu CP, Yu JC, Sun CA, et al (2008). Tumor susceptibility and prognosis of breast cancer associated with the G870A polymorphism of CCND. Breast Cancer Res Treat, 107, 95-102.

Zeybek U, Yaylım I, Ozkan NE, et al (2013). Cyclin D1 gene G870A variants and primary brain tumors. Asian Pac J Cancer Prev, 14, 4101-6.

Zhang Q, Song F, Zheng H, et al (2013). Association between single-nucleotide polymorphisms of BRAF and papillary thyroid carcinoma in a Chinese population. Thyroid, 23, 38-44.

Zheng Y, Shen H, Sturgis EM, et al (2001). Cyclin D1 polymorphism and risk for squamous cell carcinoma of the head and neck: a case-control study. Carcinogenesis, 22, 1195-9. 